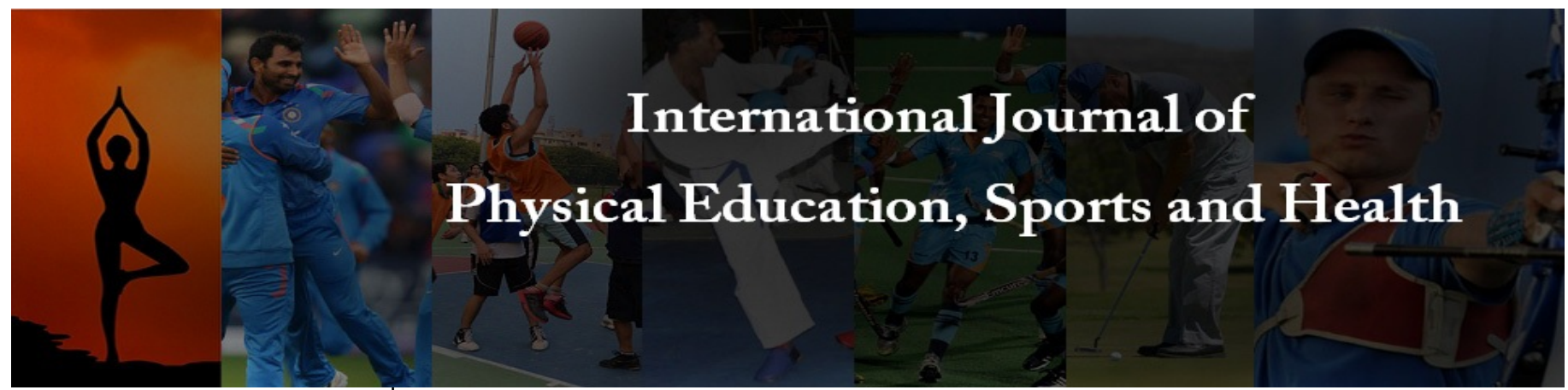

P-ISSN: 2394-1685

E-ISSN: 2394-1693

Impact Factor (ISRA): 5.38

IJPESH 2022; 9(1): 361-367

(C) 2022 IJPESH

www.kheljournal.com

Received: 28-11-2021

Accepted: 30-12-2021

Dr. Emmanuel Osei Sarpong Department of HPERS, University of Education,

Winneba, P. O. Box 25 ,

Winneba, Ghana
Corresponding Author: Dr. Emmanuel Osei Sarpong Department of HPERS,

University of Education,

Winneba, P. O. Box 25,

Winneba, Ghana

\section{Physical activity participation variables as predictors of cardiorespiratory fitness of Greater Accra fitness club members}

\section{Dr. Emmanuel Osei Sarpong}

DOI: https://doi.org/10.22271/kheljournal.2022.v9.i1f.2398

\section{Abstract}

Regular participation in physical activity improves health and well-being. This study therefore sought to establish the relationship between physical activity participation variables and cardiorespiratory fitness levels of members in Ghanaian fitness Clubs. A descriptive correlational design was used for the study. The sample for the study was 546 Club Members from 18 fitness clubs randomly selected from clubs within the Greater Accra Region of Ghana. Questionnaire and Cooper '12 minutes' walk/run test were used to gather data for the study. Inferential statistics of Pearson Product Moment Correlation Coefficient and Multiple Regression were used to test hypotheses at 0.05 level of significance.

The findings showed that:

1. (74.9\%) of the club members possess minimum levels of cardiorespiratory fitness (CRF) needed to develop health whilst (25.1\%) had low levels that needed improvement

2. Positive significant relationships existed between CRF and Physical Activity Index (PAI) (' $r$ '=.324, $\mathrm{p}=.000)$, Exercise Equipment and Machines (EEM) (' $r$ ' $=.178, p=.000)$, Variety of Physical Activity (VPA) (' $\mathrm{r}$ '=.115, $\mathrm{p}=.007$ ) while no positive significant relationship existed between CRF and Mode of Instruction (MOI) (' $r$ ' $=.065, \mathrm{p}=.178$ all 2-tailed; and

3. (14.1\%) of CRF was predicted by all variables ( $\mathrm{R}$ square $=.141)$

The study concluded that members in Ghanaian fitness clubs had minimum levels of CRF required for health development implying that improvements in fitness levels can be achieved if the right knowledge on the specific aspects of exercise prescription is applied. It was recommended that stakeholders in the Ghanaian fitness industry should collaborate to institute national policies for the organization of mass sports.

Keywords: physical activity, participation variables, predictors, cardiorespiratory fitness, health development

\section{Introduction}

Physical inactivity is the fourth leading risk factors for global mortality and estimated to cause $6 \%$ of deaths worldwide (Keyvan, Khoo, \& Morris, 2015) ${ }^{[28]}$. Half of the world's older population is considered to be physically inactive, (Jamie et al., 2016) ${ }^{[25]}$. It is therefore very crucial to find out if individuals involved in physical activity participation are reaping the benefits.

Physical activity is defined as any bodily movement undertaken by the skeletal muscles requiring energy for its execution and increases energy expenditure beyond basal levels (Caspersen, Powell \& Christenson, 1985; Haanstra \& Kamper, 2011) ${ }^{[17,23]}$ with regular involvement in moderate to intense levels contributing to maintaining wellness (Blair \& Connelly, 1996; Burton, Khan \& Brown 2011; Ratzlaff, 2012; The British Journal of Sports Medicine, 2012) ${ }^{[13,16,39,43]}$.

The level of physical activity engaged in by individuals however, varies considerably, based on personal lifestyle and other factors and can be classified as low, medium and, high" (Physical Activity Guidelines for Americans, (PAGA) 2008) while people who are active live longer, healthier lives, more productive and more likely to avoid illnesses and injuries associated with hypokinetivity (www.publichealth.gc.ca: 2011; PAGA, 2008).

Measurement of Physical Activity (PA) is difficult, but some researchers have utilized a wide range of methods which are classified into four general categories namely; calorimetry, 
physiological markers, mechanical and electronic motion detectors and occupational and leisure-time survey instruments (Bouchard, Shephard \& Stephens, 1994) ${ }^{[14]}$. Several Organizations like The World Health Organization (WHO, 1971), The Centers for Disease Control and Prevention (CDC, 1985) and The American College of Sports Medicine (ACSM, 1990) and individuals like Clarke (1967) [19] have submitted philosophical definitions of physical fitness, all with emphasis on having vigour and energy to perform work and exercise, pursue leisure and take care of emergency (Pate, 1983; McArdle, Katch and Katch (2011), Caspersen et al., (1985) [17]; Dominic and Dikki, (2011); Perry, 2012) ${ }^{[34,30,17,20,35] .}$.

Typically, physical fitness is related to health development and motor skill performance to include cardiorespiratory endurance, body composition, muscular strength, muscular endurance and flexibility using various test batteries as standardized assessment tools to connect people to the achievement and maintenance of health-enhancing levels of physical fitness (Meredith \& Welk, 2007; Siedentop, 2007) ${ }^{[31,}$ 42]

Cardiorespiratory fitness which otherwise could be referred to as cardiovascular endurance or aerobic fitness is the ability of the heart, lungs and vascular network to deliver oxygen to the working muscles and the ability of the muscles to utilize the oxygen to sustain moderate to high intensity activity (Hewitt, 2007; Perry, 2012; Caspersen et al., 1985) ${ }^{[24,35,17]}$. ACSM (2005) ${ }^{[3]}$, stated that cardiorespiratory endurance (CRE) is considered health related because low levels of it have been consistently linked with markedly increased risk of premature death from all causes, especially heart disease. One of the indicators of cardiorespiratory fitness is the amount of oxygen the human body is able to utilize per minute of physical activity, which shows the oxygen carrying capacity of the cells (Otinwa, 2005; Quinn, 2009) [33] and considered generally as the best measure for a person's physical fitness and overall health.

Further, Aires, Silva, Silva, Santos, Ribeiro \& Mota (2010) ${ }^{[1]}$, reviewed the relationship between CRF and levels of PA from sedentary to very vigorous intensities using accelerometers among students aged 11-18 and found that CRF correlated with vigorous and very vigorous PA levels and total amount of PA and also concluded that, low levels of CRF strongly correlated with obesity, which highlights the importance of increasing CRF for a protective effect. Tucker (2011) [44] found a relationship between FITNESSGRAM PA and SelfReported Physical Activity Questionnaire (SRPAQ) and also reported that the SRPAQ measures correlated poorly in childhood and adolescence studies due to recall biases. Church, Earnest, Skinner and Blair (2007) ${ }^{[13]}$, found a strong association between increasing levels of PA and fitness levels among sedentary, overweight or obese postmenopausal women with elevated blood pressure. There is the need therefore, to establish the relationship among cardiorespiratory fitness and several factors of physical activity participation variables (physical activity index, mode of instruction, exercise equipment and machines as well as variety of physical activity) which affect the overall health and well-being. The study would lead to the development of a national physical activity plan for promoting physical activity in Ghana and also for designing; conducting and evaluating fitness programmes for Ghanaians aged 18-64.

\section{Hypotheses of the Study}

1. There is no significant relationship between reported

physical activity index and cardiorespiratory fitness of members in Ghanaian fitness clubs.

2. There is no significant relationship between mode of exercise instruction and the cardiorespiratory fitness of members in Ghanaian fitness clubs.

3. There is no significant relationship between use of exercise equipment and cardiorespiratory fitness of members Ghanaian fitness Clubs.

4. There is no significant relationship between variety of physical activity experienced and cardiorespiratory fitness of members in Ghanaian fitness Clubs.

5. The independent variables (physical activity participation variables) will not be good predictors of cardiorespiratory fitness.

\section{Methodology}

The descriptive correlational study design (University of North Carolina, 2008) ${ }^{[45]}$ was employed in this study as no attempt was made to manipulate, control or interfere with the variables but to determine the relationship among them and how these variables predict the fitness levels of Ghanaian fitness club members. The multistage sampling technique was used to select a total 546 participants from 18 Keep-Fit Clubs in the Greater Accra Region of Ghana. The study employed two main types of instruments: questionnaire and standardized physical fitness test measurements (Cooper walk/run test).The instruments were validated and tested for reliability. The study employed descriptive statistics of percentage to describe the demographic characteristics of the study participants. The Pearson Product Moment Correlation was used to establish the relationship between the variables under study as depicted by hypotheses $1-4$. To determine the predictive capacity of the variables under study, the stepwise multiple regression analysis was used to analyse hypothesis 5 at an alpha level of $p<0.05$. The SPSS version 20 was the statistical package for the analysis

\section{Results}

Table 1: Frequency Distribution of Members by Reported Physical Activity Index (RPAI), Reported Mode of Instruction (RMOI), Reported Exercise Equipment and Machines (REEM), and Reported Variety of Physical Activity

\begin{tabular}{|c|c|c|}
\hline Variable & Frequency & Percent \\
\hline${ }^{\mathbf{1} R P A I}$ & & \\
\hline Sedentary & 2 & 0.4 \\
\hline Lightly Active & 65 & 11.9 \\
\hline Moderately Active & 244 & 44.7 \\
\hline Very Active & 188 & 34.4 \\
\hline Extremely Active & 47 & 8.6 \\
\hline${ }^{2}$ RMOI & & \\
\hline Poor & 20 & 3.7 \\
\hline Average & 250 & 45.8 \\
\hline Very Good & 153 & 28.0 \\
\hline Excellent & 123 & 22.5 \\
\hline${ }^{3}$ REEM & & \\
\hline No Equipment & 431 & 78.9 \\
\hline Not -Well Equipped & 107 & 19.6 \\
\hline Well -Equipped & 6 & 1.1 \\
\hline Very -Well Equipped & 2 & 0.4 \\
\hline 'RVPA & & \\
\hline Monotonous & 174 & 31.9 \\
\hline Somewhat Varied & 272 & 49.8 \\
\hline Varied & 60 & 11.0 \\
\hline Very Varied & 40 & 7.3 \\
\hline N $=546$ r
\end{tabular}


Table 1 (1) revealed that most patrons in Greater Accra fitness clubs live active lifestyles because $87.7 \%$ reported at least the minimum amount of physical activity required to promote and maintain health. Table 1 (2) indicated that only 20 (3.7\%) of the members received poor fitness instruction while 250 (45.8\%), 153 (28.0\%) and 123 (22.5\%) received average, very good and excellent instruction from their fitness instructors respectively. This implies that members are empowered to exercise on their own at home and also confident to tell others about physical activity and its benefits. Table 1 (3 and 4) also indicated that most of the fitness clubs $78.9 \%$ do not have equipment while $19.6 \%$ are not well equipped. Only $1.5 \%$ have some equipment. The implication is that this lack of exercise equipment and machines will not allow variety of activities needed for total body development. It therefore stood to reason that majority of the members $81.7 \%$ reported that their activities are not varied.

Table 2: Correlation ' $r$ ' between Cardiorespiratory Fitness (CRF) and Reported Fitness Participation Variables of Physical Activity Index (PAI), Mode of Instruction (MOI), Accessibility of Exercise Machine (EEM) and Variety of Physical Activity (VPA) of Members

\begin{tabular}{|c|c|c|c|c|}
\hline Variable CRF (VO 2max ) & PAI & MOI & EEM & VPA \\
\hline Pearson Correlation 'r' & .324 & .065 & .178 & .115 \\
\hline Sig. (2 -tailed) & .000 & .129 & $.000^{*}$ & $.007^{*}$ \\
\hline $\mathrm{N}$ & 546 & 546 & 546 & 546 \\
\hline
\end{tabular}

*Correlation is significant at the 0.05 level (2-tailed)

Table 2 indicated that there was a strong and positive correlation between all the four variables and fitness levels of members in Greater Accra fitness clubs as depicted here: PAI (.324), MOI (.065), EEM (.178) and VPA (.115).

Hypothesis One: There is no significant relationship between reported physical activity index and cardiorespiratory fitness of members in Ghanaian fitness clubs

Physical activity levels had a positive and strong relationship with the cardiorespiratory fitness of members in Ghanaian fitness Clubs. The significant (2- Tailed) value of .000 is less than .05 and therefore suggests that there is statistically significant correlation between reported physical activity levels and cardiorespiratory fitness hence the null hypothesis is rejected.

Hypothesis Two: There is no significant relationship between mode of exercise instruction and cardiorespiratory fitness of members in Ghanaian fitness clubs.

The results from table 2 also indicated that reported mode of instruction received by members had positive and strong relationship with CRF. However, the significant (2-Tailed) value of .129 is greater than .05 and therefore suggests that there is no statistically significant relationship between reported mode of instruction and CRF leading to the acceptance of the null hypothesis.

Hypothesis Three: There is no significant relationship between availability and use of exercise equipment and cardiorespiratory fitness of members in Ghanaian fitness clubs.

The results from Table 2 further revealed that reported availability and use of exercise machines had a low and positive relationship with the CRF of members. The significant (2-Tailed) value of .000 is less than .05 so the null hypothesis is rejected and therefore suggests that there is statistically significant relationship between reported availability and use of exercise machines had a strong and positive relationship with the CRF.

Hypothesis Four: There is no significant relationship between variety of physical activity experience and cardiorespiratory fitness of members in Ghanaian fitness clubs.

Lastly, results from Table 2 showed that reported variety of physical activity had a strong and positive relationship with CRF of members. The (2-Tailed) significant value of .007 is less than .05 and therefore suggests that there is statistically significant correlation between reported variety of physical activity and CRF leading of the rejection of the null hypothesis.

Table 3: Regression Analysis for Reported Fitness Participation Variables of PAI, MOI, EEM, VPA and Cardiorespiratory Fitness Levels $\left(\mathrm{VO}_{2 \max }\right)$ among Members in Ghanaian Fitness Clubs

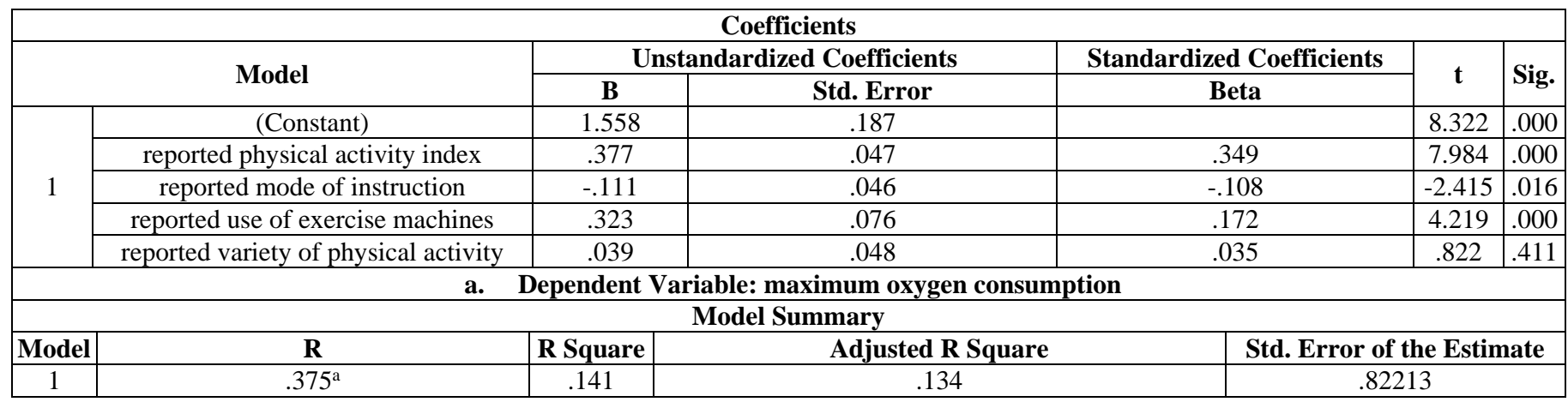

Predictors: (Constant), reported variety of physical activity, reported accessibility of exercise machines, reported physical activity index, reported mode of instruction

From the composite table, Reported PAI contributed 34.9\%, while Reported MOI 10.8\%; reported accessibility to exercise equipment, $17.2 \%$, while reported variety of physical activity $3.5 \%$. The implication is that RPAI contributed most to CRF (34.9\%), followed by REEM (17.2\%), thirdly, RMOI (10.8\%) and lastly RVPA (3.5\%). The weakly composite relation of Mode of Exercise Instruction indicates that when the mode is improved it may contribute greater than what is reported and could predict cardiorespiratory fitness better.

From the results, only $14.10 \%$ of the Cardiorespiratory Fitness measured in maximum oxygen consumption $\left(\mathrm{VO}_{2 \max }\right)$ could be predicted by PAI, MOI, EEM and VPA alone (R square of 0.141 ) which means that other factors play a much bigger role than the selected independent variables. This implies that the independent variables were not good predictor of CRF. 
Hypothesis 5: The independent variables (physical activity participation) will not be good predictors of CRF.

Results from table 13 indicated that the independent variables of PAI, MOI, EEM and VPA together are not good predictors of cardiorespiratory fitness (14.1\%).

\section{Discussion}

The study (Table 1 ) revealed that majority of the members in fitness clubs reported being active by following the general exercise recommendations for apparently healthy adults. Majority of the clubs reported having no exercise equipment and machine while others had no facilities to ensure variety. The discussion of the results is presented below on the bases of each hypothesis

Hypothesis one: Relationship between Physical Activity Index and Cardiorespiratory Fitness.

The results from Table 2 showed that reported physical activity levels had a positive and strong relationship with the cardiorespiratory fitness of members in Ghanaian fitness Clubs. The significant (2- Tailed) value of .000 is less than .05 and therefore suggests that there is statistically significant correlation between reported physical activity levels and cardiorespiratory fitness. Therefore, the $\mathrm{H}_{0} 1$ stating that there is no significant relationship between reported physical activity levels and body composition is rejected. This implies that individual who engage in moderate to vigorous levels of physical activity can improve their levels of cardiorespiratory endurance. The findings supported other studies (Bouchard et al., 1994; Blair \& Connelly, 1996 ${ }^{[13]}$; The Public Health Agency of Canada, 2011; Sjosten et al., 2012) ${ }^{[14,13,43]}$ who stated that individuals who engage in regular and appropriate levels of physical activity to develop cardiorespiratory endurance, musculoskeletal fitness, and optimal body fat level appear to improve their basic energy levels and place themselves at lower risk for developing the common diseases of affluence, including heart disease. Similarly, Garber et al., (2011) [21] and ACSM, (2010a) [6] corroborated that improvements in CRF are attenuated with exercise frequencies greater than three days in a week and at a frequency of $45-85 \%$ of maximal heart rate. Ghanaian fitness club members should therefore realize that it is not enough to engage in physical activity because greater benefits could only be accrued when the correct mix of FITT is religiously followed.

Hypothesis Two: Relationship between Mode of Exercise Instruction and Cardiorespiratory Fitness

The results from Table 2 also indicated that reported mode of instruction received by members had positive and strong relationship with CRF. However, the significant (2-Tailed) value of .129 is greater than .05 and therefore suggests that there is no statistically significant relationship between reported mode of instruction and CRF. Therefore, the $\mathrm{H}_{0} 2$ stating that there is no significant relationship between reported mode of instruction and CRF was upheld. The implication here is that individuals can receive good instructions from their instructors but may not utilize them to improve their fitness levels. It can also mean that individuals report subjectively on the instructions received in order to save the face of their instructors. The findings are in consonance with that of Kahn et al., (2002) ${ }^{\text {[27] }}$ who opined that insufficient provision of knowledge and promotion of awareness of exercise prescription recommendations to promote behaviour change leads to non-engagement of adults in recommended amounts of physical activity, higher dropout rates of individuals enrolled in exercise programmes which can affect the levels of CRF. Researchers (Bandura, 1997; Williams et al., 2005; Wojcicki et al., 2009) ${ }^{[12,46,47]}$ were of the view that the value placed on specific outcomes influences behaviour change in that for an individual to adopt and maintain a programme of regular physical activity, he must feel both confident that he will be able to do the physical activity and feel that the behaviour will lead to a valued outcome. The results are also in line with the study of Grant et al. (2014) ${ }^{[22]}$ who revealed that in South Africa, participants in physical activity programmes can test and monitor their fitness levels without supervision from sports scientists and this was corroborated by Sarpong, Apaak \& Dominic (2015) [40]. When an information is received and it is not used practically it can only lead to best intentions. It is therefore advisable that participants of fitness centers in Ghana pay rapt attention to their instructors' directions during training sessions so that they could pick the necessary things required to exercise on their own at all times since they only meet once a week.

Hypothesis Three: Relationship between Availability and use of Exercise Equipment and Cardiorespiratory Fitness

The results from Table 2 further revealed that reported availability and use of exercise machines had a low and positive relationship with the CRF of members. The significant (2-Tailed) value of .000 is less than .05 and therefore suggests that there is statistically significant relationship between reported availability and use of exercise machines had a strong and positive relationship with the CRF. Therefore, the $\mathrm{H}_{0} 3$ which states that there is no significant relationship between reported availability and use of exercise machines and CRF is rejected. The implication is that availability and use of exercise machines can bring about variety in physical activity leading to improvement in fitness levels. The finding supports other studies (Ajisafe, 1980; Arhein, 2000; Peter, 2001; Obiyemi et al., 2002) [2, 37, 32] which stressed that availability and use of exercise equipment and facilities facilitates instructions, enhance training, promote skill acquisition and promote physical fitness. Even though there existed a positive relationship between availability and use of exercise machines and equipment, the Ghanaian situation is such that majority of the clubs have no equipment needed to ensure total development.

Hypothesis Four: Relationship between Variety of Physical Activities and Cardiorespiratory Fitness

Lastly, results from Table 2 showed that reported variety of physical activity had a strong and positive relationship with CRF of members. The (2-Tailed) significant value of .007 is less than .05 and therefore suggests that there is statistically significant correlation between reported variety of physical activity and CRF. Therefore, the $\mathrm{H}_{0} 4$ stating that there is no significant relationship between reported variety of physical activity and CRF is rejected. The implication is that variety of physical activity ensures total body development and recovery that culminates into increases in fitness levels and development in overall health and well- being. The finding supports other studies (ACSM, 2007: ACSM, 2010) ${ }^{[5,6]}$ that the daily workout has a combination of aerobic, strength and flexibility exercises because these help to develop all parts of the body and also allow for recovery and improve levels of physical fitness. Also, Armstrong, et al., (2005) ${ }^{[11]}$ and Garber et al., (2011) ${ }^{[21]}$ concluded that rhythmic, aerobic type 
exercise involving large muscle groups with four different modes (variety) of physical activity: endurance activities requiring minimal skill and physical fitness, vigorous intensity endurance activities requiring minimal skill, endurance activities requiring skill and recreational sports are recommended for improving cardiorespiratory fitness. Lastly, the 2008 physical activity guidelines for Americans formulated by The ACSM (2007) ${ }^{[5]}$ have been updated. The updated recommendation now specifies that moderate and vigorous intensity activities are complimentary in the production of health benefits and that a variety of activities can be combined to meet the recommendations. These recommendations were not explicit in the 1995 guidelines. $\mathrm{Li}$

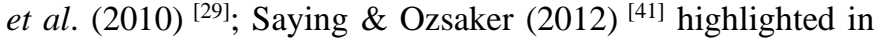
support of the findings that the type of exercise training, age, gender and body composition were related with CRF. Therefore, fitness programmes should be highly motivating through varieties of physical activities to encourage continuity and improvement of CRF. Variety is the spice of life. However, the lack of innovation on the part of majority of the fitness club instructors have resigned members to monotonous activities like road runs and games play.

Hypothesis Five: Predictive Capacity of Physical Activity Index, Mode of Exercise Instruction, Availability and Use of Exercise Machines and Variety of Physical Activities and Cardiorespiratory Fitness

Results from Table 3 indicated that the independent variables of PAI, MOI, EEM and VPA are not good predictors of cardiorespiratory fitness (14.1\%). The finding is in conformity with that of (Mendis, Puska, \& Norrving, 2011) that heredity, age, sex and the individual potential for fitness influenced cardiovascular health. Buckingham, (2007) [15] concluded that though increasing levels of PA predicted cardiovascular health, knowledge on the specific aspects of exercise prescription should not be lacking. This is corroborated by Pescatello et al., (2004) [36] that future research must focus on specific aspects of exercise prescription (FITT) which has the greater potential to improve cardiorespiratory fitness. This implies that an individual may report or even engage in regular physical activity, vary their activities and use good exercise equipment and yet will not improve their levels of cardiorespiratory fitness if the right mix of exercise prescription principles are not applied. Also factors like age, sex and heredity that affect cardiorespiratory fitness are not modifiable and their influence should not be overlooked (Li, 2010; Ozsaker, 2012; Joshi et al., (2015) ${ }^{[29,41,}$ 26]

\section{Conclusions}

The following conclusions were arrived at based on the findings of the study:

1. Members in Ghanaian fitness clubs led active lifestyles and this influenced their fitness levels positively.

2. Members in Ghanaian fitness clubs had minimum levels of CRF required for health promotion and maintenance. However, the zones of interpretation revealed that with advancement in age as depicted by the age profile of the participants, education on the need to engage regularly in health enhancing levels of physical activity should be embarked upon.

3. Members in Ghanaian fitness clubs had minimum levels $\mathrm{BC}$ required for reducing the risk levels associated with obesity. However, the fat distribution patterns shown by skin fold measures indicated that $78 \%$ of Ghanaians have their excess fat around the abdominal region thereby increasing the risk level for developing cardiovascular disease. This calls for mass education on how to maintain healthy body weight and fat percentages through regular involvement in the appropriate levels of physical activity and positive lifestyle of healthy nutrition.

4. The independent variables (physical activity index, mode of instruction received, availability and use of exercise equipment and variety of physical activity engaged in) were not good predictors of CRF and BC as other factors that were not modifiable through lifestyles changes might have predicted the dependent variables better.

\section{Recommendations}

The following recommendations were made based on the findings of the study:

1. The Executive Committee of the Greater Accra Fitness Clubs Association (GAFCA) should form a monitoring group that will from time to time visit clubs in their jurisdiction to look at how activities are organized and offer the needed advice so that the levels of fitness will be improved and /or maintained.

2. Policy makers in Education and Health should ensure the introduction of fitness for health development as a new course of study at all levels of education especially colleges of Education and Health in order to produce healthy man-power for the nation.

3. The Physical Education Departments of University of Education, Winneba; University of Cape Coast and the Kwame Nkrumah University of Science and Technology should do collaborative research to ascertain the predictive capacity of other dependent variables not used in the study in order to widen the scope of knowledge in this area of specialization.

4. There is need to encourage older adults of 60 years and above to be more involved in group physical activity since this is the age of isolation and inactivity leading to higher rate of degeneration.

\section{Implications of Findings}

The implication is that improvements in fitness levels can be achieved if the right knowledge on the specific aspects of exercise prescription is applied. Stakeholders of the fitness industry in Ghana should therefore encourage the training, certification and licensure of fitness instructors in order to be professionally competent. Furthermore, members in Ghanaian fitness clubs should be educated constantly on the health implications of active lifestyle.

\section{Reference}

1. Aires L, Silva P, Santos MP, Ribeiro JC, Mota J. Intensity of physical activity and body mass index in youth. Journal of Physical Activity and Health. 2010;7(1):54-59. Doi.org/10.1123/jpah.7.1.54

2. Ajisafe MO. Teaching Physical education and health education. Ibadan: Macmillan Nigeria Publishers Limited, 1980.

3. American College of Sports Medicine. ACSM's Guidelines for Exercise Testing and Prescription $\left(7^{\text {th }}\right.$ Ed.) Philadelphia: Lippincott Williams \& Wilkins, 2005.

4. American College of Sports Medicine (ACSM), choosing a group fitness instructor: New ACSM Position Stand on general Exercise Programming, 2006.

5. American College of Sports Medicine (ACSM). ACSM's Guidelines for Exercise Testing and Prescription ( $7^{\text {th }} \mathrm{Ed}$.) 
Philadelphia: Lippincott Williams \& Wilkins, 2007.

6. American College of Sports Medicine (ACSM). ACSM's Guidelines for Graded Exercise Testing and Prescription (8 ${ }^{\text {th }}$ Ed.). Philadelphia: Lippincott Williams \& Wilkins, 2010a.

7. American College of Sports Medicine. The recommended quantity and quality of exercise for developing and maintaining cardiorespiratory and muscular fitness in healthy adults. Journal of Exercise Science and Sports Medicine. 2010b;30:975-991.

8. American College of Sports Medicine. ACSM's Resources for Clinical Exercise Physiology. Baltimore: Lippincott William \& Wilkins, 2010c.

9. American College of Sports Medicine. Manual for Guidelines for Exercise Testing and Prescription $\left(6^{\text {th }}\right.$ Ed.). Philadelphia: Lippincott William \& Wilkins. 2010d.

10. American College of Sports Medicine \& American Heart Association (ACSM \& AHA). Exercise and acute cardiovascular events: Placing the risks into perspective. Journal of Sports Science and Exercise Medicine. 2007;39:889-897.

11. Armstrong LE, Brubaker PH, Whaley MH, Otto RM. ACSM's Guidelines for Exercise Testing and Prescription $\left(7^{\text {th }}\right.$ Ed.). Baltimore (MD): Lippincott Williams \& Wilkins, 2005, 366.

12. Bandura A. Self-Efficacy: The Exercise of Control. New York: Freeman, 1997, 604.

13. Blair SI, Connelly J. How much physical activity should we do? The case for moderate amounts and intensities of physical activity. Research Quarterly for Exercise and Sport. 1996;67(2):193-205.

14. Bouchard C, Shephard RJ, Stephens T. Physical Activity, Fitness, and Health: International Proceedings and Consensus Statement. Champaign, IL: Human Kinetics, 1994.

15. Buckingham D. Beyond Technology: Children's Learning in the Age of Digital Media (translated into Spanish). Cambridge: Polity Press, 2007.

16. Burton NW, Khan A, Brown WJ. How, where and with whom? Physical activity context preferences of three adult groups at risk of inactivity; British Journal of Sports Medicine. 2011;46:1125-1131.

17. Caspersen CJ, Powell KE, Christenson GM. Physical activity, exercise, and physical fitness: Definitions and Distinctions for health-related research. Public Health Reports. 1985;100(2):126-131.

18. Church TS, Earnest CP, Skinner JS, Blair SN. Effects of different doses of physical activity on cardiorespiratory among sedentary, overweight or obese postmenopausal women with elevated blood pressure: a randomized control trial. JAMA. 2007;297(19):2081-2091. DOI: 10.1001/jama.297.19.2081

19. Clarke HH. Application of Measurement to Health and Physical Education. Englewood Cliffs, New Jersey: Prentice -Hall Inc. 1967.

20. Dominic OL, Dikki CE. A meta- analysis of Arterial blood pressure response to resistance exercise and its implications for cardiovascular health. The Nigerian Journal of Guidance and Counselling. 2011;16(1):68-80.

21. Garber CE, Blissmer B, Deschenes MR, Franklin BA, LaMonte MJ, Lee I-Min, et al. Quantity and Quantity of Exercise for Developing and Maintaining Cardiorespiratory, Musculoskeletal and Neuromotor Fitness in Apparently Healthy Adults. Journal of Sports Exercise Medicine. 2011;43(7):1334-13.
22. Grant CC, Janse van Rensburg DC, Pepper MS, Du Toit PJ, Wood PS, Ker J, et al. The correlation between health-related fitness of healthy participants measured at home as opposed to fitness measured by sports scientists in a laboratory, South African Family Practice. 2014;56(4):235-239.

DOI: $10.1080 / 20786190.2014 .953888$

23. Haanstra TM, Kamper SJ. Increasing physical activity in healthy adults: a meta- analysis; British Journal of Sports Medicine. 2011;46:998-999.

24. Hewitt MJ. Writing an exercise prescription. In: Rakel D. Integrative Medicine. $2^{\text {nd }}$ Ed. Philadelphia, Pa: Saunders Elsevier; chap 90. 2007.

25. Jamie S, McPhee D, French P, Dean J, Nazroo J, Neil P, et al. Physical activity in older age: Perspectives for healthy aging and frailty, 2016. Doi: 10.1007/s10522016-9641-0

26. Joshi AA, Wingkar K, Joshi A. Comparative study of cardio respiratory fitness, BMI, waist to hip ratio in female medical students amongst two ethnic groups. India Journal of Basic and Applied Medical Research. 2015;4(2):93-98.

27. Kahn EB, Ramsey LT, Brownson RC, Heath GW, Howze EH, Stone EJ, et al. The effectiveness of interventions to increase physical activity. A systematic review. American Journal of Preventive Medicine. 2002;22(4):73-107.

28. Keyvan M, Khoo S, Tony M. Motives for adult participation in physical activity: Type of activity, age, and gender. BMC Public health. 2015;15:66. https://doi.org/10.1186/s12889-015-1429-7.

29. Li Y, Hu X, Zhang Q, Liu A, Fang H, Hao L, et al. The nutrition based comprehensive intervention study on childhood obesity in China, a randomized controlled trial. BMC Public Health. 2010;10:229.

Doi.org/10.1136/1471-2458-10-229

30. McArdle WD, Katch FI, Katch VL. Exercise physiology: Energy, Nutrition, and Human Performance ( $6^{\text {th }}$ Ed.). Philadelphia: Lippincott Williams \& Wilkins. 2011;26:511.

31. Meredith MD, Welk GJ. Fitnessgram/Activitygram: Test Administration manual: The Cooper Institute $\left(4^{\text {th }}\right.$ ed). Champaign, IL: Human Kinetics, 2007.

32. Obiyemi OO, Adesoye AA, Ogunsanwo BA. The relationship of selected factors and achievement of organizational goals of Lagos State Council. Ilorin Journal of Health, Physical Education and Recreation and Dance. 2002;3(2):21-30.

33. Otinwa GO. Maximum oxygen consumption of healthy African male in United States of America. European Journal of Scientific Research. 2005;12(I):82-86.

34. Pate FM. Predicting decrements in military performance due to inadequate nutrition. National Academies Press. 1983.

35. Perry M. What is physical fitness; Builtlean. 2012 Dec 02. www.builtlean.com/2012/02/12/physical-fitness/

36. Pescatello LS, Franklin BA, Fagard R, Farquhar WB, Kelley GA, Ray CA. Exercise and hypertension. Medicine \& Science in Sports and Exercise, 2004, 533553.

37. Peter GA. Administration and Organisation of Physical and Health Education, Sports and Recreation. Ibadan: Yew Printers, 2001.

38. Quinn E. 12 minute fitness test for endurance: Sports medicine, 2008. 
www.sportsmedicine.about.com/od/fitnessevalandassess ment/a/12MinRun.html

39. Ratzlaff CR. Good news, bad news: sports matter but occupational and household activity really matter- sports and recreation unlikely to be a panacea for public health. British Journal of Sports Medicine. 2012;46(10):699-701. DOI: 10.1136/bjsports-2011-090800

40. Sarpong EO, Apaak D, Dominic OL. Reported physical activity levels and equipment use as predictors of body composition of members in Ghanaian fitness clubs. Reaserachjournali's Journal of Public Health. 2015;1(4):7-16.

41. Sayin OC, Ozsaker M. The comparison of some physical fitness for individual and team athletes. Nigde University Journal of Physical Education and Sports Sciences. 2012;16:102-111.

42. Siedentop D. Introduction to physical education, fitness, and sport (6 ${ }^{\text {th }}$ ed.). Boston: McGraw - Hill, 2007.

43. Sjosten N, Kivimaki M, Singh-Manoux A, Ferrie JE, Goldberg M, Zins M, et al. Change in physical activity and weight in relation to retirement: the French GAZEL Cohort Study, British Medical Journal, 2012.

44. Tucker W. New Workout takes fitness to the Go- Go. Vegan Health and Fitness magazine, 2011.

45. University of North Carolina. Understanding research design. Research for nursing practice. Chapel Hill School of Nursing, 2008. Retrieved from www.unc.edu/courses/2008fall/nurs/377/960/research_de sign/topic2.html

46. Williams DM, Anderson ES, Winett RA. A review of the outcome Expectancy construct in physical activity research. Journal of Behavioural Medicine. 2005;29(1):70-79.

47. Wojcicki TR, White SM, McAuley E. Assessing outcome expectations in older adults: The multidimensional outcome expectations for exercise scale. Journal of Gerontology Behaviour Psychology and Social Science. 2009;64(1):33-40. 